\title{
Successful treatment of refractory Barrett's neoplasia with hybrid argon plasma coagulation: a case series
}

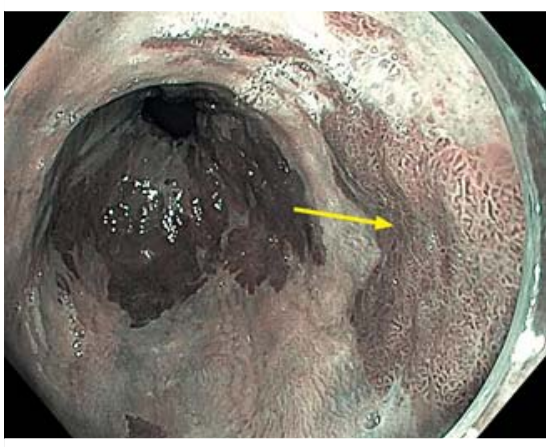

- Fig. 1 Endoscopy with narrow band imaging showing a Barrett's segment after five sessions of radiofrequency ablation. There was a raised area (yellow arrow) of intramucosal cancer.

A 60-year-old woman with Barrett's esophagus (Prague class C8M10) with flat high grade dysplasia underwent radiofrequency ablation (RFA) therapy. She underwent four sessions with the circumferential balloon and one treatment with the focal 90 ablation catheter for a total of five sessions. Sessions were performed every 3 months and the patient adhered to maximal acid suppression therapy.

The patient returned for a sixth session (15 months from the start of therapy). Endoscopy showed a 5-cm area of salmon-colored mucosa remaining. There was also a slightly raised $2-\mathrm{cm}$ island that was suspicious for residual neoplasia ( $\triangleright$ Fig. 1, arrow). The decision was made to perform extensive biopsies to rule out progression of disease. Results showed intramucosal cancer in the raised area while the remaining distal Barrett's segment was nondysplastic.

Given the presence of refractory Barrett's mucosa, the decision was made to switch therapy to hybrid argon plasma coagulation (hAPC). The neoplastic island was removed using band ligation endoscopic mucosal resection technique; histology showed intramucosal cancer with negative margins. The EMR

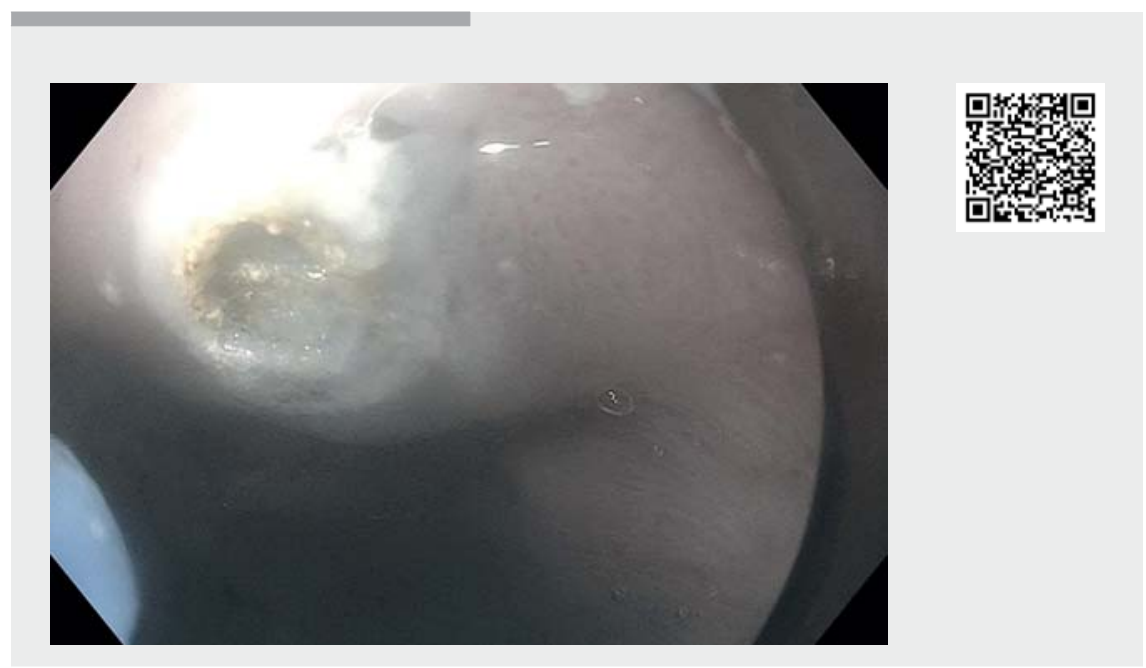

Video 1 Endoscopic mucosal resection (EMR) of a raised Barrett's area, hybrid argon plasma coagulation (hAPC) of the EMR defect, and hAPC of the remaining flat Barrett's mucosa.
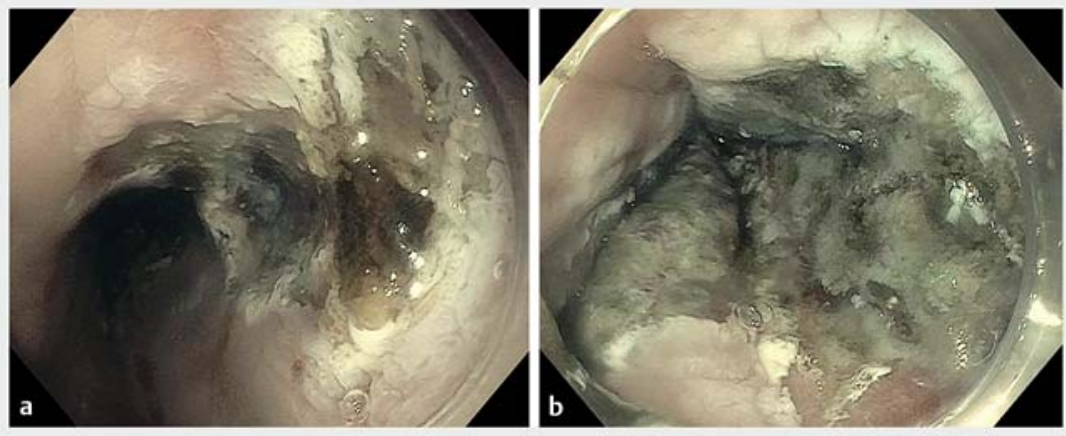

- Fig. 2 Treatment of the Barrett's segment that was refractory to radiofrequency ablation. a Endoscopic mucosal resection (EMR) of the raised area, and hybrid argon plasma coagulation (hAPC) of the EMR defect. b The remaining flat, nondysplastic Barrett's mucosa also underwent hAPC.

defect was treated with hAPC. The mucosa was raised using a submucosal injection (Erbejet, Effect 50; Erbe Elektromedizin $\mathrm{GmbH}$, Tübingen, Germany) and ablated at $40 \mathrm{~W}$ ( $\triangleright$ Video 1 ). The remaining distal nondysplastic Barrett's mucosa was also treated with hAPC at $60 \mathrm{~W}$ (> Fig. 2).
Follow-up endoscopy 3 months later showed minimal islands, which were retreated with hAPC ( $\triangleright$ Fig.3). Follow-up endoscopy 6 months from the start of hAPC therapy showed complete eradication of intestinal metaplasia ( $>$ Fig.4), as confirmed by histology from biopsies. 
- Table 1 Information for five patient who were refractory to radiofrequency ablation with our without cryotherapy and who were successfully treated with hybrid argon plasma coagulation.

\begin{tabular}{|c|c|c|c|c|c|c|c|}
\hline Patient & $\begin{array}{l}\text { Patient age, } \\
\text { years/sex }\end{array}$ & $\begin{array}{l}\text { Initial Prague } \\
\text { class and grade } \\
\text { of dysplasia }\end{array}$ & $\begin{array}{l}\text { Treatment prior } \\
\text { to hAPC } \\
\text { (no. of sessions) }\end{array}$ & $\begin{array}{l}\text { Prague class } \\
\text { prior to hAPC }\end{array}$ & $\begin{array}{l}\text { CE-D achieved } \\
\text { prior to hAPC }\end{array}$ & $\begin{array}{l}\text { Sessions } \\
\text { of hAPC, } n\end{array}$ & $\begin{array}{l}\text { CE-IM achieved } \\
\text { after hAPC }\end{array}$ \\
\hline 1 & $60 / F$ & $\begin{array}{l}\text { C } 8 M 10 \\
\text { HGD }\end{array}$ & RFA (5) & C1M5 & No & 2 & Yes \\
\hline 2 & $51 / \mathrm{M}$ & $\begin{array}{l}\text { C7M8 } \\
\text { LGD }\end{array}$ & $\begin{array}{l}\text { RFA (4) } \\
\text { Cryo (3) }\end{array}$ & $\mathrm{C} 2 \mathrm{M} 4$ & Yes & 2 & Yes \\
\hline 3 & $72 / F$ & C8M10 & $\begin{array}{l}\text { RFA (4) } \\
\text { Cryo (2) }\end{array}$ & C6M7 & No & 3 & Yes \\
\hline 4 & $76 / \mathrm{M}$ & C7M7 & $\begin{array}{l}\text { RFA (4) } \\
\text { Cryo (2) }\end{array}$ & $\mathrm{C} 2 \mathrm{M} 3$ & No & 2 & Yes \\
\hline 5 & $75 / M$ & C4M5 & RFA (3) & $\mathrm{C} 2 \mathrm{M} 3$ & No & 2 & Yes \\
\hline
\end{tabular}

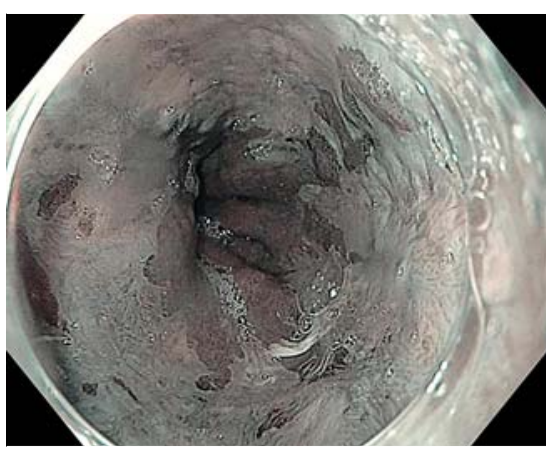

Fig. 3 Follow-up endoscopy 3 months after one session of hybrid argon plasma coagulation (hAPC) showing minimal islands remaining.

The patient tolerated all procedures well and had no post-procedural pain.

This case shows that hAPC is an option when RFA has failed. In our institution we have used hAPC to successfully treat five consecutive cases of disease that was refractory to RFA with or without cryotherapy ( $>$ Table $\mathbf{1}$ ).

Endoscopy_UCTN_Code_CPL_1AH_2AK

\section{Competing interests}

Dr. Benias is a consultant for Medtronic. Dr. Trindade is a consultant for Olympus America and Pentax America, and has received research support from Ninepoint Medical.

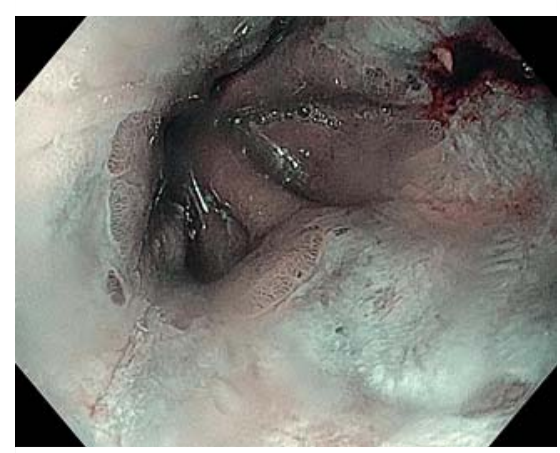

- Fig. 4 Endoscopy after two sessions of hybrid argon plasma coagulation showed complete eradication of intestinal metaplasia and dysplasia.

The authors

Arvind J. Trindade, Diana Wee, Praneet Wander, Molly Stewart, Calvin Lee, Petros C. Benias, Matthew J. McKinley Division of Gastroenterology, Long Island Jewish Medical Center, Zucker School of Medicine at Hofstra/Northwell, Northwell Health System, New Hyde Park, New York, United States

\section{Corresponding author}

\section{Arvind J. Trindade, MD}

Division of Gastroenterology, Long Island Jewish Medical Center, Zucker School of Medicine at Hofstra/Northwell, Northwell Health System, 270-05 76th Avenue, New Hyde Park, NY 11040, United States

Fax: +1-718-470-5509

arvind.trindade@gmail.com
Bibliography

DOI https://doi.org/10.1055/a-1119-1030

Published online: 27.2.2020

Endoscopy 2020; 52: 812-813

(c) Georg Thieme Verlag KG

Stuttgart · New York

ISSN 0013-726X

\section{ENDOSCOPY E-VIDEOS}

https://eref.thieme.de/e-videos

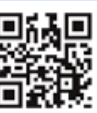

Endoscopy E-Videos is a free access online section, reporting on interesting cases and new techniques in gastroenterological endoscopy. All papers include a high quality video and all contributions are freely accessible online.

This section has its own submission website at https://mc.manuscriptcentral.com/e-videos 